\title{
Operations Research Techniques in Management of Samples Transport to the Clinical Laboratory
}

\author{
Ventura Pedret Salvador ${ }^{1}$, Solé Llop Esther ${ }^{2}$, Rovirosa Reverte Monica ${ }^{1}$, \\ Triviño Molla Carmen ${ }^{1}$ \\ ${ }^{1}$ Laboratori Clìnic Metropolitana Sud Institut Catalá de la Salut, L'Hospitalet de Llobregat, Barcelona, Spain \\ 'Laboratorio de Análisis Clínicos, Hospital General “Obispo Polanco” de Teruel Servicio Aragonés de Salud, \\ Teruel, Spain \\ Email: sventura@ambitcp.catsalut.net
}

Received 12 October 2014; revised 16 November 2014; accepted 8 December 2014

Copyright (C) 2014 by authors and OALib.

This work is licensed under the Creative Commons Attribution International License (CC BY). http://creativecommons.org/licenses/by/4.0/

(c) (i) Open Access

\section{Abstract}

Currently, the model is based on the Clinical Laboratory. It is a great centre that performs almost all of the techniques. Thanks to the automation of them. These laboratories receive samples from centres that often are some kilometers away. Time spent between collection and processing must be as short as possible and this is a requirement to care about in order to process the samples in optimal conditions. Transport logistic factor is essential to achieve the right balance between optimal quality of the specimens and efficiency in managing resources. Our laboratory attends 96 centres in an area of high population density and intricate road network. We considered planning the transport paths and timetables based on a branch of mathematics called Operations Research. The aim was to plan routes from and to the laboratory that covered the specimen transport with the shortest possible time. Material and Methods: In January 2012 we planned restructuring transport routes according to two methods applied to solve the TSP problems: the nearest neighbour method and the edge classified. Although these are not top methods, they are useful to control the time spent between the sample collection centre and the laboratory applying operational research methods. Results: We identified that $12 \%$ of the paths used excessive time to reach the laboratory (more than 90 minutes). These routes were modified applying the nearest neighbour method.

\section{Keywords}

Operations Research, Clinical Laboratory, Travelling Salesman Problem

Subject Areas: Clinical Trials, Drugs \& Devices 


\section{Introduction}

The majority of the clinical laboratories have evolved to laboratories of big volume, totally computerised and automated. These new stage has a big potential and will be able to offer innovative techniques like genomics and proteomics.

Likewise, the possibility of manage great clinical information stored, will be able to influence the useful scientific knowledge in epidemiology and other matters. Experts in Clinical Laboratory are prepared to participate of way but active in clinical investigation. This model has his weak points ([1]-[3] mainly in preanalitical process.

The need of performing big volumes of analysis, imply the samples transport from distant laboratory places. This requires that the samples arrival time to the laboratory was as short as possible, in order to analyse it in optimal conditions [4].

The logistic factor of the transport is essential to achieve the best quality of the sample and correct management efficiency.

Our laboratory attends 96 centers of samples extraction in a high density demographic and intricate road network zone. We have planning the transport routes and spend time using one of the branches of the mathe- matics called: "Operative Investigation”. The aim of this process was to design the shortest time transport routes from the extraction centres that come and finish in the laboratory.

The mathematical problem is different if it requires one or more transport vehicles. When a vehicle alone is sufficient, the name of the process is "Travelling Salesman Problem" (TSP). The situation is equivalent to these that the trader visits diverse cities. The aim of the salesman is to be one time in each city, finishing the route in the starting point and that the route will be as short as possible. The technical expression to resolve the TSP is to find "Hamiltonian circuits of minimum cost", although his resolution will have some difficulties [4].

When required more than one vehicle to cover these routes is receives the name "Vehicle Routing Problem “(VRP), whose study started Dantzig and Ramser in 1959 [5].

The classical technique to solve the problems VRP is linear programming that treats like subsets the diverse circuits type TSP.

In January 2012, our Laboratory plan a new organisation of the routes of transport, adapt two of the existent methods to solve the TSP problems: the method of the "nearest neighbour" and the method of "classified edges" that, still not being the most leading methods, allow to apply the Operative Investigation techniques in the control of the route time between the centre of extraction and the laboratory [6].

We develop the following steps:

1) Data collection of the transport times:

- To make a matrix of provisional time (provisional Matrix of time (Tprov) between all the centres employing Google *Maps.

- Identification of each centre with *Ci.

- Identification of the laboratory with code CL.

- Step 1: To calculate the times of route between a point of origin * Ci and the arrival CL,

- Step 2: To adjust the real time. This need to make a new matrix (T) that included the half times of wait, time registered:

Being:

$$
\begin{aligned}
& \mathrm{T}=\mathrm{f} \bullet \mathrm{T} \text { prov } \\
& \mathrm{T}=\text { Matrix adjusted } \\
& \mathrm{f}=\text { Factor of time }(\mathrm{f}) \\
& \mathrm{T} \text { prov. }=\text { provisional Matrix's time }
\end{aligned}
$$

Ones we had made this, we would have matrix $\mathrm{T}$ suitable and complete incorporating the half times of wait.

2) To make a map between routes and the codes of each centre

In the matrix, we should add the real times of route between all the centres; afterwards we should add in the map some corresponding secondary matrices to the routes employed by the vehicles of transport. This mapping will allow us to identify the possible missing centre and to include it in the matrix of time.

3) Calculation of the optimum routes and to make a comparative study with the routes of that moment.

- For each route, calculate the current time of resorted to split of the matrix T and of the *mapping.

- Apply resolution algorithms to solve the problem TSP (Travelling Salesman Problem) or use the *software *GAMS: www.gams.com. In our case resort to the method of the "Nearest Neighbour".

- For each route, calculate the difference of time between the current route and the route solution of the TSP. 
4) Analysis of the results obtained: Taking into account the following factors

$t$ e $=$ Time of stability of the sample;

tr $=$ Time of route;

$\boldsymbol{t} \mathbf{l}=$ maximum spend time between the sample extraction and the arrival to the laboratory;

$\boldsymbol{t} \mathbf{i}=$ half time from the extraction in the centre ${ }^{*} \mathrm{Ci}$ until the car *valise collects the sample.

The aim is that $\boldsymbol{t} \mathbf{z} \approx \boldsymbol{t}$, being $\boldsymbol{t i}=\max i \in R\{\boldsymbol{t} \mathbf{l}\}+\boldsymbol{t r}$.

\section{Results Obtained}

A matrix of time is obtained in which we can observed the majority of the routes adapted to the exposed equation ( $\boldsymbol{t} \mathbf{i}=\max i \in R\{\boldsymbol{t} \mathbf{}\}+\boldsymbol{t r}$ ). However, we identify that a $12 \%$ of the routes had employed more than 90 minutes in his route. That is considered excessive and, consistently, modified using the Neighbour most nearer.

\section{Conclusion}

The control of the times in the transport routes by Operative Investigation is highly recommended. It allows better control of the routes employed and deviations identification. Ones applied these technique, is easy to follow-up in the daily routine.

\section{References}

[1] Plebani, M. and Carraro, P. (1997) Mistakes in a Stat Laboratory: Types and Frequency. Clinical Chemistry, 43, 13481351.

[2] Bonini, P., Plebani, M., Ceriotti, F. and Rubboli, F. (2002) Errors in Laboratory Medicine. Clinical Chemistry, 48, 691698.

[3] Mugueta Uriaque, M.C., Alegre Martínez, E., Varo Cenarruzabeitia, N., González Hernández, A., Gil Calvo, M.J. and Monreal Marquiegui, I. (2006) Record of Incidents and Calculation of Quality Indicators in the Preanalitycal Phase. Química Clínica, 25, 75-80.

[4] Belles Sampera, J., Ventura Pedret, S., Gomis Castellvi, M. and Miquel March Amengual, J. (2012) Sample Collection Routes and Errors in the Analitical Process. Revista del Laboratorio Clínico, 5, 10-17.

[5] Dantzig, G.B. and Ramser, J.H. (1959) The Truck Dispatching Problem. Management Science, 6, 80-91. http://dx.doi.org/10.1287/mnsc.6.1.80

[6] Applegate, D.L., Bixby, R.E., Chvátal, V. and Cook, W.J. (2007) The Traveling Salesman Problem. Princeton University Press, Princeton. 